TAO, Vol. 12, No. 1, 41-62, March 2001

\title{
Inventory of Aircraft Emissions over the Taiwan Area
}

\author{
Po-Hsiung Lin ${ }^{1}$, Wei-So Sun ${ }^{1}$, and Jen-Ping Chen ${ }^{1, *}$ \\ (Manuscript received 12 September 2000, in final form 22 February 2001)
}

\begin{abstract}
The inventory of aircraft emissions over the Taipei Flight Information Region (FIR) has been developed with 1997 as the baseline year. We first analyze the spatial and temporal distribution of flight frequency based on the official civil aviation monthly reports, airline flight schedules and pilots' on-air reports. Fuel consumption and trace-gas emissions are then calculated by using the engine performance database of the International Civil Aviation Organization (ICAO) and a few other data sources. The emission inventory is further classified according to the flight types (domestic or international), aircraft types (passenger jets, cargo jets or propeller aircraft), as well as the state of aircraft operation (idle, takeoff, climb-out, cruise and approach/landing). Engine types, number of engines per aircraft, as well as engine performance at different operation states are all considered in estimating the emission rates.

The emission rates of six trace chemicals $\left(\mathrm{NO}_{\mathrm{x}}, \mathrm{CO}, \mathrm{CO}_{2}, \mathrm{~S}, \mathrm{HC}\right.$ and $\mathrm{H}_{2} \mathrm{O}$ ) are estimated for all flight routes and airports, and at different cruise altitudes. To get a sense of their relative importance, we compared the total emissions from aircraft over the Taipei FIR with those from the ground transport in Taiwan. The ratios we obtained are $14.5 \%$ for $\mathrm{NO}_{\mathrm{x}}, 9.5 \%$ for $\mathrm{S}, \mathrm{CO}_{2}$ and $\mathrm{H}_{2} \mathrm{O}, 0.86 \%$ for $\mathrm{CO}$, and $0.42 \%$ for $\mathrm{HC}$. About $85 \%$ of the $\mathrm{NO}_{\mathrm{x}}$ and $80 \%$ of the $\mathrm{S}, \mathrm{CO}_{2}$ and $\mathrm{H}_{2} \mathrm{O}$ were emitted into the upper troposphere, whereas most of the $\mathrm{CO}(74 \%)$ and $\mathrm{HC}(60 \%)$ were produced on the surface. A further comparison shows that the amount of aircraft-produced $\mathrm{NO}_{\mathrm{x}}$ over the Taiwan area is about $69 \%$ of those produced over Mainland China, and aircraft-produced sulfur is about $1.1 \%$ of those produced globally.
\end{abstract}

(Keywords: Emission inventory, Civil aircraft, Taipei FIR)

\section{INTRODUCTION}

Aircraft emissions have many impacts on global environment, such as the emissions of

\footnotetext{
${ }^{1}$ Department of Atmospheric Sciences, National Taiwan University, Taipei, Taiwan, ROC

${ }^{*}$ Corresponding author address: Prof. Jen-Ping Chen, Dept. of Atmospheric Sciences, National Taiwan University, \#1, section 4, Roosevelt Road, Taipei, Taiwan, ROC; E-mail: jpchen@ @ater.as.ntu.edu.tw
} 
greenhouse gases, depletion of stratospheric ozone, production of tropospheric ozone, and the formation of cirrus-like contrail clouds. All these factors are relevant to the change of radiation budgets in the atmosphere-earth system. For example, anthropogenic carbon dioxide $\left(\mathrm{CO}_{2}\right)$ may have contributed to about $1.5 \mathrm{~W} \mathrm{~m}^{-2}$ radiative forcing in 1992 , and about $1.3 \%$ of this forcing (i.e., $0.02 \mathrm{~W} \mathrm{~m}^{-2}$ ) could have resulted from aviation emissions of $\mathrm{CO}_{2}$ (IPCC 1996). Aircraft emissions also cause the formation of contrails, which cover about $0.1 \%$ of the Earth's surface and much larger percentages on the regional scale. The radiative forcing from contrails is about $0.02 \mathrm{~W} \mathrm{~m}^{-2}$ on a global average (IPCC 1996), but can be an order of magnitude higher on a regional scale (Fortuin et al. 1995). Such aircraft-induced radiative forcing may increase by about 5 fold by 2050, due to the high growth rate in aviation activity.

World passenger traffic on scheduled airlines has doubled during the past ten years (IATA 1996a). At the same time, aviation fuel consumption has reached about $3 \%$ of the fuel used worldwide, or $13 \%$ of the fossil fuel used in worldwide transportation. Such fast growth has accelerated not only current conditions but also future prospects of aviation impacts. Scenarios of global aviation emissions have been studied and compared among National Aeronautics and Space Administration of the United Sates (Baughchum et al. 1996b), the Deutsches Zentrum fur Luft- und Raumfahrt and the European Abatement of Nuisances Caused by Air Transport/ European Commission (Gardner 1998). They estimated a 4\% average growth rate of aviation fuel consumption from 1992 to 2015. The Intergovernmental Panel on Climate Change (IPCC 1999) summarized the conclusions of these projects for policymakers in helping them grasp the current scientific understanding of aviation effects on global atmosphere.

The projects mentioned above have provided a global view of the effects of aviation emissions. It seems that the current effects are small on a global scale. But, one should not ignore the importance of aircraft emissions, because the effect on a local or regional scale is much stronger. According to the report of Air Transport Action Group (ATAG 1997), the air raffic growth rates in East Asia and the western Pacific region were $10.1 \%$ between 1985 and 1995 and are expected to be about 7.4\% between 1995 and 2010. These rates are about twice the global average. In Taiwan, the annual growth rate between 1991 and 1996 was over 20\% (CAA 1998), also much higher than the world average of 5\% per year. Furthermore, as indicated by its key position in the East Asia/western Pacific region shown in Fig. 1, the Taipei Flight Information Region (FIR) hosts several of the busiest international and ranscontinental flight routes in Asia. The route between Hong Kong and Taipei alone carries more than onethird of the flights in Asia (IATA 1996b). One can thus expect a high local impact from the aircraft emissions over Taiwan. We therefore intend to estimate the inventory of aircraft emissions over the Taiwan area in order to provide crucial information for atmospheric modeling and government policymaking. Note that the northwestern portion of the Taipei FIR actually overlaps with the Shanghai FIR, so there could be some flights going through that area but which are not accounted for in this study.

We first investigate the spatial (horizontal and vertical) and temporal (annual, seasonal, weeklong and diurnal) distributions of both domestic and international flights over the Taipei FIR. The average emissions from a single aircraft are then estimated by considering the fuel flow rate and emission indices of different engine types for different operation states (i.e., idle, takeoff, climb-out, cruise, and approach/landing) using dataset from the International Civil 


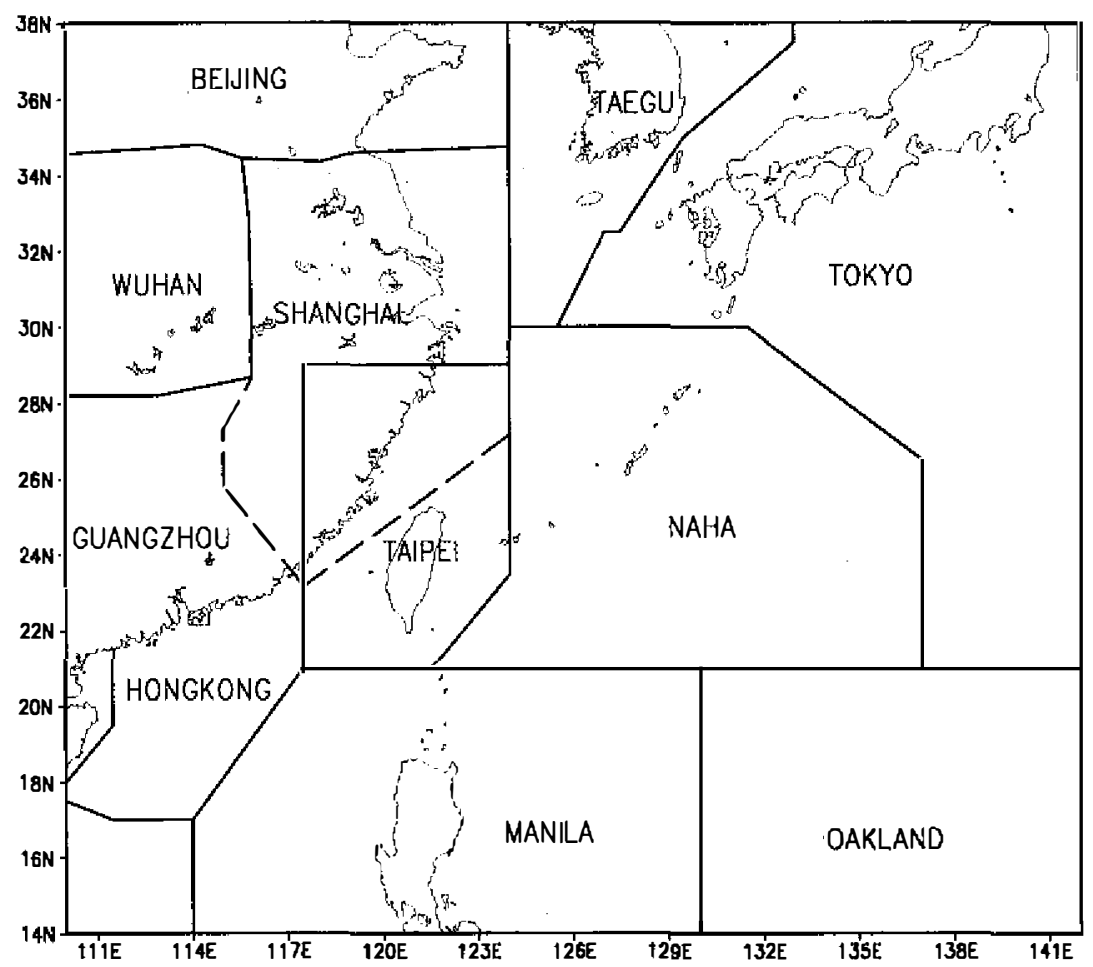

Fig. 1. Geographical distribution of Flight Information Regions (FIR) in the western Pacific region.

Aviation Organization (ICAO). Combining the flight information and emission rates, we obtain the emission rates of several trace gases along different flight corridors (both domestic and international) and airports over the Taipei FIR. Finally, these emission inventories are compared with those of land transportation as well as the aircraft emissions over Mainland China.

\section{METHODOLOGY FOR EMISSION ESTIMATION}

Ideally, the emissions during one complete flight operation can be obtained according to the equation:

$$
\boldsymbol{e}_{i}=\boldsymbol{n} \sum_{k=1}^{5}\left(\boldsymbol{q}_{i k} \cdot \boldsymbol{f}_{k} \cdot \boldsymbol{t}_{k}\right)
$$

where $e$ is the amount of emission ( $\mathrm{g}$ ), $\boldsymbol{i}$ is a chemical compound (such as $\mathrm{NO}_{\mathrm{x}}$ and $\mathrm{SO}_{2}$ ), $\mathrm{n}$ is the number of engines per aircraft, $k$ is the engine operation mode (idle, takeoff, climb-out, cruise, approach/landing), $q$ is the emission index (mass of pollutants produced by buming a unit mass of fuel, in $\left.\mathrm{g} \mathrm{kg}^{-1}\right), f$ is the fuel flow rate $\left(\mathrm{kg} \mathrm{s}^{-1}\right)$, and $t$ is the operation time (s). There are seven engine operation modes in one landing and takeoff (LTO) cycle: taxi-out, takeoff, 
climb-out, cruise, approach, landing and taxi-in (ICAO 1993). The taxi-out and taxi-in modes are generally combined into a single mode called "idle." The approach and landing modes are also combined into a single mode because of their similar emission indices. Besides the "cruise" mode, all other engine modes are defined as operations at altitudes below 1,000 feet. Table 1 lists the mode-specific engine power setting and operation time except for the cruise mode, for which the operation time depends on individual flight schedule and cruise speed. The emission factor $e$ and the fuel flow rate $f$ in Eq. (1) are engine-dependent parameters.

Equation (1) gives the complete emission calculation for one flight operation between two airports (i.e., one LTO cycle). In reality, however, it is difficult to trace the specifics of operation for each single flight (such as the aircraft and engine types, engine performance, payload, operation time of different engine modes, type of fuel used, and fuel consumption, etc.). A compromise solution is to use averaged values for the parameters in Eq. (1) by classifying aircraft into 4 major types: passenger jet, cargo jet, propeller aircraft, and military aircraft. Equation (1) is then modified as:

$$
\boldsymbol{E}_{i j}=\sum_{j=1}^{3}\left(N_{j} \sum_{k=1}^{S}\left(Q_{i j k} \cdot F_{j k} \cdot \boldsymbol{T}_{j k}\right)\right),
$$

where $E$ is the average amount of emission (g), $i$ indicates the chemical compound, $j$ indicates the aircraft type, $N$ is the average amount of engines, $\boldsymbol{k}$ indicates the status of engine operation mode, $\boldsymbol{Q}$ is the average emission index $\left(\mathrm{g} \mathrm{kg}^{-1}\right), \boldsymbol{F}$ is the average fuel flow rate $\left(\mathrm{kg} \mathrm{s}^{-1}\right)$, and $\boldsymbol{T}$ is the average operated time (s). In this study we did not estimate the emissions from military aircraft, so $j=1$ to 3 refers to passenger jet, cargo jet and propeller aircraft.

Five main data sources are used in deriving the above parameters. They are: a) monthly reports of the Civil Aeronautics Administration (CAA) of the Ministry of Transportation and Communications, Republic of China (hereinafter, "CAA report"); b) weekly timetables of domestic airlines (hereinafter, "domestic timetable"); c) pilot's way-point reports; d) ICAO engine emissions databank (hereinafter, "ICAO databank"); and e) emission content for propeller aircraft from Baughcum et al. (1996). The CAA report contains the operating information of all airports in Taiwan, including the LTO cycles, passenger and cargo flight frequency, passenger and cargo loads, aircraft types, etc. From this data set we obtained the engine types

Table 1. Average engine performances (rated output) and operation times under different operation modes as defined in the ICAO exhaust emissions databank.

\begin{tabular}{ccc}
\hline Mode & Rated Output (\%) & Time (minutes) \\
\hline Idle & 7 & 26.0 \\
Take-off & 100 & 0.7 \\
Climb-out & 85 & 2.2 \\
Approach/Landing & 30 & 4.0 \\
\hline
\end{tabular}


and the average number of engine per aircraft $(N)$ for international flights in the Taipei FIR. The domestic timetables contain not only the time schedule but also the aircraft type for all domestic flights. By combining it with the CAA report, one can obtain the specifics about domestic traffic, including the ratio between jets and propeller aircraft as well as the annual fuel consumption.

The pilot's way-point report is a communication record required by the Air Traffic Services Division in the CAA for aircraft flying above 10000 feet and passing through specific locations in the route (i.e., the way-points; solid round points in Fig. 2). The main contents are the reporting time, departure time and airport, destination airport, current altitude and speed, as well as the previous and next way-points. An interactive software interface is developed for extracting records from the way-point database according to specified criteria. From this database we obtained certain information about international flights, such as the cruise speed, flight frequency in a certain route, the distribution of flight altitudes, and whether the flight is

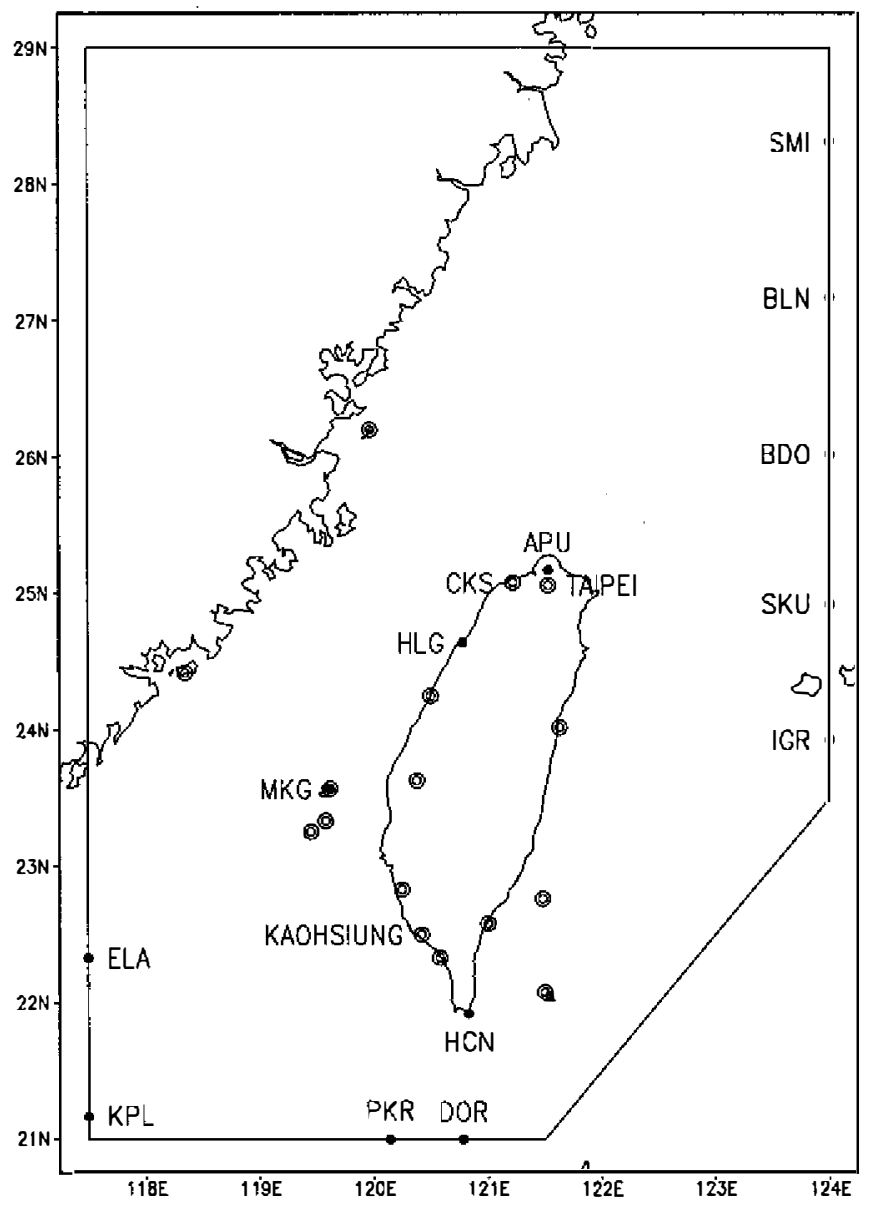

Fig. 2. Way-points (solid circle) and airports (empty circle) in the Taipei FIR. 
departing/arriving or just passing through.

The last two data sources provide most of the information on emission indices, fuel flow rates and operation time for surface and near surface operations. Since the early 1970 s, engine manufacturers started measuring emissions to demonstrate compliance with regulations developed for the airport vicinity. ICAO established emission indices for several pollutants based on measurements performed on 86 types of engines (ICAO 1995), and 16 of them are commonly used on the commercial aircraft operated in the Taipei FIR according to the CAA report. Because of a lack of information on propeller aircraft in the ICAO databank, we also referred to the report by Baughcum et al. (1996) to obtain emission content for propeller aircraft. Details of the parameters in Eq. (2) are given below.

\subsection{Types and Number of Engines}

According to the CAA monthly report, sixteen types of jet engine operated in the Taipei FIR were found to appear in the ICAO databank. As given in Table 2, the average number of engines of the passenger jet and cargo jet is calculated by weighting with the flight frequencies for each aircraft type and model. The cargo jets are separated out as they account for a significant portion (11.5\%) of the international air traffic. In addition, these aircraft are equipped with more engines ( 3.42 per aircraft) to handle the normally heavier payloads.

The third aircraft type that needs to be accounted for is the propeller craft, all of which are used for domestic transportation in the Taipei FIR. As will be shown in Section 4, the propeller aircraft cannot be ignored in the emission estimation because of their relatively high LTO frequency (see Table 2), even though their flight distance (thus cruise-mode operation time) are relatively short. There are 6 types of propeller passenger aircraft in operation in the Taipei FIR, but only one engine type (for aircraft model ATR-72) was registered in the ICAO databank. Fortunately, ATR-72 is the dominant type of propeller aircraft operating between local cities and, in particular, offshore islands. We therefore used the emission rate for ATR-72 aircraft to represent all propeller crafts operated in the Taipei FIR.

\subsection{Emission Index and Fuel Flow Rate}

Later we will estimate aircraft emissions of six chemicals, including the major products of fossil fuel combustion $-\mathrm{CO}_{2}$, water vapor $\left(\mathrm{H}_{2} \mathrm{O}\right)$ and nitrogen oxides $\left(\mathrm{NO}_{\mathrm{x}}\right)$, products due to inefficient combustion - carbon oxide (CO) and hydrocarbons $(\mathrm{HC})$, and fuel-impurity related products - sulfur compounds ( $\mathrm{S}$, mainly in the form of $\mathrm{SO}_{2}$ ). From the ICAO databank and Baughcum et al. (1996), we obtained factors $\boldsymbol{Q}$ and $\boldsymbol{F}$ of these chemicals (index $\boldsymbol{i}=1 \sim 6$ ) for three jet aircraft types (index $\boldsymbol{j}=1 \sim 3$ ) under different engine operation modes (index $\boldsymbol{k}=$ $1 \sim 4)$.

Table 3 shows the average emission indices $Q$ for different chemicals as well as the fuel flow rates $\boldsymbol{F}$. By multiplying the emission index with fuel flow rate, we can derive the mean emission rates as those given in Table 4. Note that the emission indices for $\mathrm{H}_{2} \mathrm{O}, \mathrm{CO}_{2}$ and $\mathrm{S}$ depend not on the engine operation mode but rather on the fuel type. From the ICAO databank and other supporting references (e.g., Zhao and Turce 1995; Brasseur et al. 1998), we obtained the values of $3.14 \mathrm{~kg} \mathrm{~kg}^{-1}, 0.4 \mathrm{~g} \mathrm{~kg}^{-1}$, and $1.23 \mathrm{~kg} \mathrm{~kg}^{-1}$ for $\mathrm{CO}_{2}, \mathrm{~S}$ and $\mathrm{H}_{2} \mathrm{O}$, respectively, for 
Table 2. Average number of engines per aircraft (with standard deviation shown in the parentheses) and LTO percentage for different aircraft types in the Taipei FIR.

\begin{tabular}{cccc}
\hline & Passenger jet & Cargo jet & Propeller aircraft \\
\hline $\begin{array}{c}\text { Average number of } \\
\text { engines }\end{array}$ & $2.36(0.7)$ & $3.42(0.5)$ & $2(0)$ \\
\hline LTO percentage & $58.7 \%$ & $3.5 \%$ & $37.8 \%$ \\
\hline
\end{tabular}

Table 3. Emission index $\left(\mathrm{g}^{\mathrm{kg}} \mathrm{kg}^{-1}\right)$ and fuel flow rate $\left(\mathrm{kg} \mathrm{s}^{-1}\right)$ under different engine operation modes for (a) passenger jet, (b) cargo jet, and (c) propeller aircraft.

\begin{tabular}{|c|c|c|c|c|c|c|c|}
\hline \multicolumn{3}{|c|}{ Engine operation mode } & Idle & Take-off & Climb-out & Approach & Cruise \\
\hline \multirow{9}{*}{$\begin{array}{c}\text { Emission } \\
\text { index } \\
\left(\mathrm{g} \mathrm{kg}^{-1}\right)\end{array}$} & \multirow{3}{*}{$\mathrm{HC}$} & (a) & 3.99 & 0.11 & 0.12 & 0.37 & $0.24^{+}$ \\
\hline & & (b) & 15.50 & 0.07 & 0.08 & 0.54 & $0.31^{+}$ \\
\hline & & (c) & 1.36 & 0.30 & 0.30 & $0.30^{+}$ & 0.30 \\
\hline & \multirow{3}{*}{$\mathrm{CO}$} & (a) & 24.82 & 0.48 & 0.57 & 2.77 & $1.67^{+}$ \\
\hline & & (b) & 47.80 & 0.19 & 0.19 & 3.81 & $2.00^{+}$ \\
\hline & & (c) & 83.57 & 6.27 & 4.50 & $4.50^{+}$ & 4.50 \\
\hline & \multirow{3}{*}{$\mathrm{NO}_{\mathrm{x}}$} & (a) & 4.27 & 27.05 & 20.92 & 9.98 & $15.45^{+}$ \\
\hline & & (b) & 3.92 & 33.16 & 24.60 & 9.80 & $17.20^{+}$ \\
\hline & & (c) & 1.50 & 15.36 & 15.07 & $6.93^{+}$ & 11.00 \\
\hline \multirow{3}{*}{$\begin{array}{c}\text { Fuel flow } \\
\text { rate } \\
\left(\mathrm{kg} \mathrm{s}^{-1}\right)\end{array}$} & \multicolumn{2}{|c|}{ (a) } & 0.17 & 1.87 & 1.51 & 0.51 & $1.01^{+}$ \\
\hline & \multicolumn{2}{|c|}{ (b) } & 0.20 & 2.44 & 2.00 & 0.65 & $1.33^{+}$ \\
\hline & \multicolumn{2}{|c|}{ (c) } & 0.14 & 0.14 & 0.14 & $0.14^{+}$ & 0.14 \\
\hline
\end{tabular}

+ Estimated under the assumption that the value for the cruise mode is the average of those for the climb-out and approach modes.

common aircraft fuels. The ICAO databank does not contain the cruise-mode $Q$ and $\boldsymbol{F}$ for jet aircraft. By checking with some airline pilots, we found it reasonable to assume the engine output (and thus the factors $Q$ and $\boldsymbol{F}$ ) during cruise mode to be the mean of those during climbout and approach/landing (see Table 1). The values obtained this way turn out to be consistent with those of Brasseur et al. (1998). The ICAO databank also lacks of the $\boldsymbol{Q}$ and $\boldsymbol{F}$ for propeller aircraft. For the emission of $\mathrm{NO}_{\mathrm{x}}, \mathrm{CO}$ and $\mathrm{HC}$ during cruise mode of propeller aircraft, we 
Table 4. Same as Table 3 but for the emission rates $\left(\mathrm{g} \mathrm{s}^{-1}\right)$.

\begin{tabular}{|c|c|c|c|c|c|c|}
\hline & & Idle & Take-off & Climb-out & Approach & Cruise \\
\hline \multirow{3}{*}{$\mathrm{HC}$} & (a) & 0.68 & 0.21 & 0.18 & 0.19 & $0.24^{+}$ \\
\hline & (b) & 3.10 & 0.17 & 0.12 & 0.35 & $0.41^{+}$ \\
\hline & (c) & 0.19 & 0.04 & 0.04 & $0.04^{+}$ & 0.04 \\
\hline \multirow{3}{*}{$\mathrm{CO}$} & (a) & 4.22 & 0.90 & 0.86 & 1.41 & $1.69^{+}$ \\
\hline & (b) & 9.56 & 0.46 & 0.38 & 2.48 & $2.66^{+}$ \\
\hline & (c) & 11.70 & 0.88 & 0.63 & $0.63^{+}$ & 0.63 \\
\hline \multirow{3}{*}{$\mathrm{NO}_{\mathrm{x}}$} & (a) & 0.73 & 50.58 & 31.59 & 5.09 & $15.60^{+}$ \\
\hline & (b) & 0.78 & 80.91 & 49.20 & 6.37 & $22.88^{+}$ \\
\hline & (c) & 0.21 & 2.15 & 2.11 & $0.97^{+}$ & 1.54 \\
\hline \multirow{3}{*}{$\mathrm{S}$} & (a) & 0.07 & 0.75 & 0.60 & 0.20 & $0.40^{+}$ \\
\hline & (b) & 0.08 & 0.98 & 0.80 & 0.26 & $0.53^{+}$ \\
\hline & (c) & 0.06 & 0.06 & 0.06 & $0.06^{+}$ & 0.06 \\
\hline \multirow{3}{*}{$\mathrm{CO}_{2}$} & (a) & 534 & 5872 & 4741 & 1601 & $3171^{+}$ \\
\hline & (b) & 628 & 7662 & 6280 & 2041 & $4176^{+}$ \\
\hline & (c) & 440 & 440 & 440 & $440^{+}$ & 440 \\
\hline \multirow{3}{*}{$\mathrm{H}_{2} \mathrm{O}$} & (a) & 209 & 2300 & 1857 & 627 & $1242^{+}$ \\
\hline & (b) & 246 & 3001 & 2460 & 799 & $1636^{+}$ \\
\hline & (c) & 170 & 170 & 170 & $170^{+}$ & 170 \\
\hline
\end{tabular}

adopted the average values for turboprops from Baughcum (1996). The emission indices for the other operation modes are not available from the above two data sources. We therefore estimate them according to the relative concentration of the gases in the engine exhaust listed in the maintenance manual provided by the TranAsia (Fushing) Airways. This maintenance manual also provides fuel flow rates during various operation modes. However, it does not provide information for the approach/landing mode. So, again, we assume the engine output during cruise mode to be the mean of those during climb-out and approach/landing, but this time deriving factors for the approach/landing mode.

\subsection{Operation Time}

The ICAO databank also provides average operation time for all but the cruise mode (Table 1), which depends on the cruise speed and flight distance. According to the way-point reports, the average cruise speed for subsonic jets is $248.7 \mathrm{~m} \mathrm{~s}^{-1}$, which is quite consistent with the $250 \mathrm{~m} \mathrm{~s}^{-1}$ given in IATAG (1998). The cruise speed for propeller craft is $130 \mathrm{~m} \mathrm{~s}^{-1}$ on average (IATAG 1998). The flight distance is calculated by measuring the length of each 
route shown in Fig. 3. Although the actual cruise time depends on weather conditions, control tower operations and aircraft mechanical conditions, they can be regarded as constants on a long-term average.

\section{TEMPORAL AND SPATIAL DISTRIBUTIONS OF FLIGHT FREQUENCY}

To obtain a detailed estimation of regional aircraft emissions, one need to know the temporal and spatial variations of flight frequencies over the airports and flight corridors. Here we present the temporal variations in four time formats (annual, monthly, weeklong, and hourly), and then the horizontal and vertical spatial distributions.

\subsection{Annual Variation}

Figure 4a shows the annual frequency (in terms of LTO cycles) of both domestic and international air traffic in the Taipei FIR from 1988 to 1999 obtained from the CAA reports. Note that the domestic flight frequency is only one half of the LTO cycles because both the

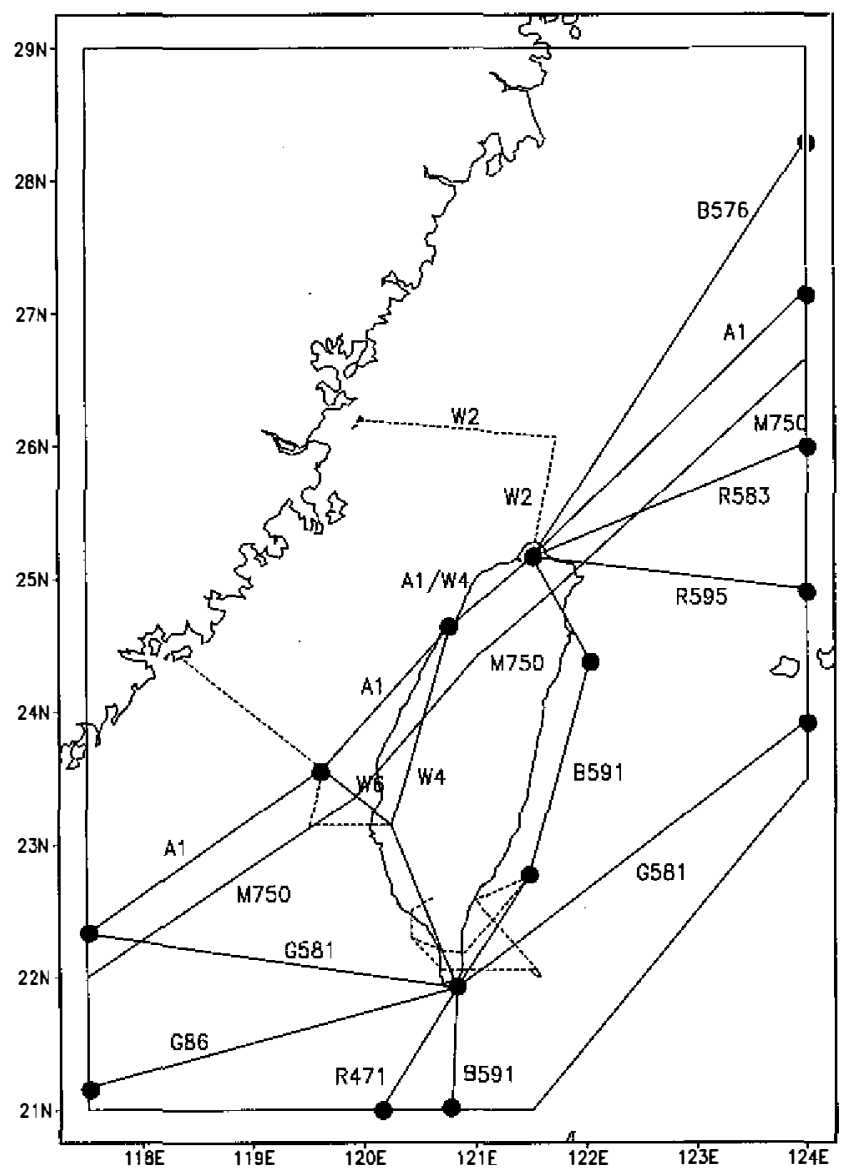

Fig. 3. Flight routes in the Taipei FIR. The dash lines represent domestic routes for offshore-island flights. 

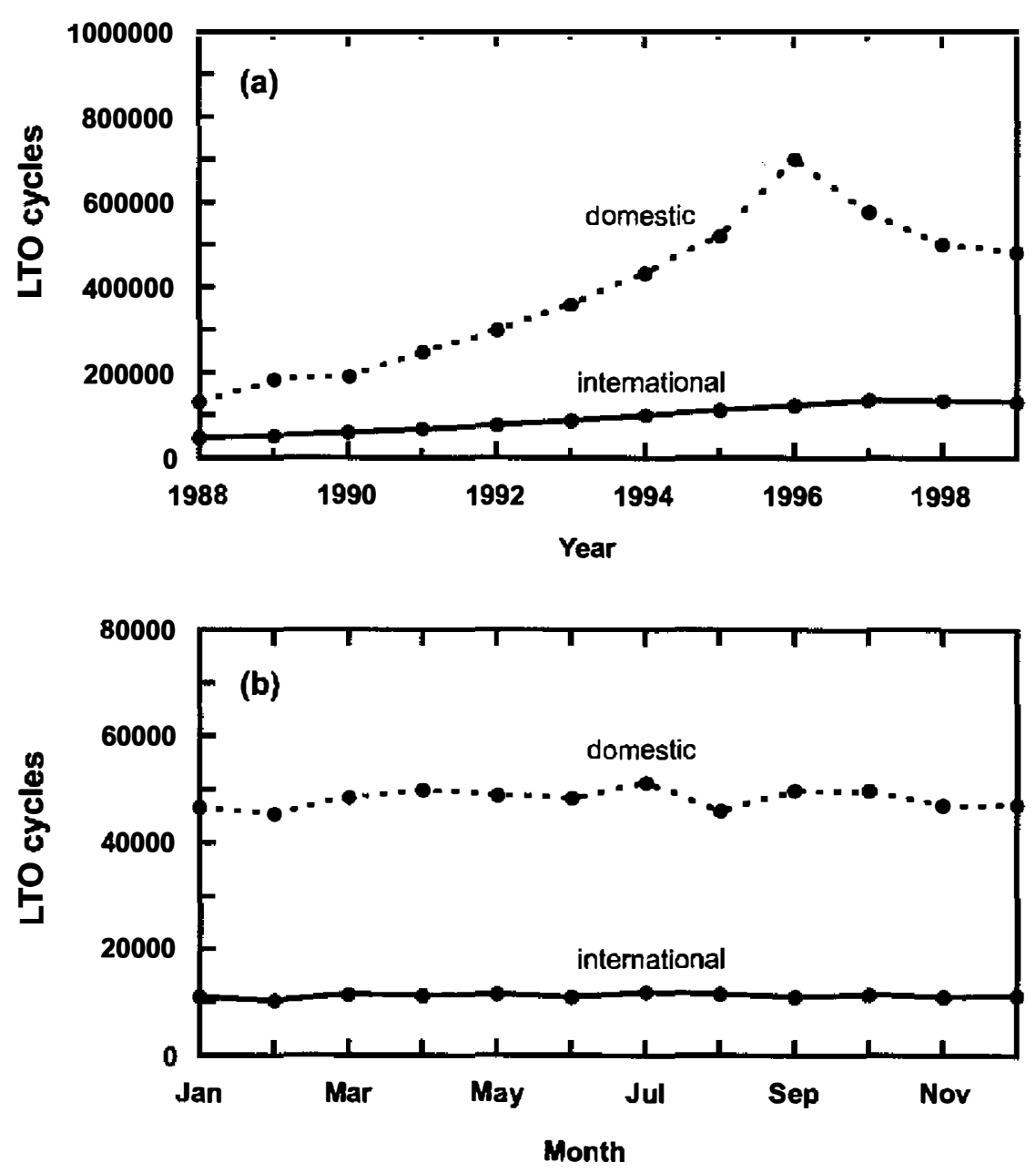

Fig. 4. Time variation of LTO cycles over the Taipei FIR. (a) Annual variation; (b) monthly variation in 1997.

landing and takeoff operations take place within the Taipei FIR; whereas for the international flights, one LTO cycle represents exactly one flight. Also note that the over-flights (passing through the Taipei FIR without touching the surface) in the international corridors are not counted in the above LTO cycles, but will be considered in the estimation of the total emissions. Between 1988 and 1997, the domestic flight frequency increased from about 130,000 LTO per year to near 580,000 LTO per year, almost doubling every five years. However, the fast growth trend subsided significantly after 1997, possibly due to over-expansion and several flight-safety incidents. During the same period, the international flights increased steadily but at a slower pace, from 47,000 LTO in 1988 to $135,000 \mathrm{LTO}$ in 1997. The domestic to international flight ratio went up from 2.8 in 1988 to 4.6 in 1996, then dropped down to 3.7 in 1998. To facilitate discussion, we choose 1997 as the baseline year for estimating the temporal and spatial variations of aircraft emissions. 


\subsection{Monthly Variation}

The monthly air traffic frequency (LTO cycles) in the Taipei FIR can be readily obtained from the CAA reports. As shown in Fig. 4b, there is no significant seasonal variation for both the domestic and international flights in the Taipei FIR. In comparison, the global average flight frequency is higher during summer and lower during winter, with the highest (5\% greater than the annual average) occurring during July and lowest (5\% less than the annual average) during January (IPCC 1999). A similar pattern can also be found for the North Pacific region. The North Atlantic region has even stronger seasonality, with about $15 \%$ higher during July and 15\% lower traffic during January than the annual average. On the other hand, the monthly variation in the Southern Hemisphere is similar to the Taipei FIR, showing essentially no seasonality.

\subsection{Weeklong and Diurnal Variations}

The daily and diurnal variations are more obvious than the monthly variations. According to the 1997 domestic timetables, Sunday is typically the busiest day of the week for domestic flights (Fig. 5a), but on Sunday the flight frequency is only about $4 \%$ higher than that during the least busy day (Wednesday). The international flight frequency, on the other hand, is slightly higher on Friday through Sunday, as well as Tuesday, than the other days. Note that in 1999 the government implemented a new official working-day policy - Saturday off every second and fourth week of the month. Since then, Friday has become the busiest day for domestic flights (about 5\% higher than on the other weekdays). This in turn eases down the traffic flow on Saturday and Sunday (now only about $2 \%$ higher than in the weekdays). The weekly schedule of international flights, however, remains unaffected.

Figure $5 \mathrm{~b}$ shows the diurnal variations of flight frequencies. Most of the domestic flights start their operation after 6:00 a.m. The flight frequency increases rather quickly and reaches a plateau of about 140 LTO per hour between 9:00 a.m. and 3 p.m. Hosting 34.5\% of the total domestic flights, the busiest Taipei Airport handles a maximum of nearly 50 landings and takeoffs in one hour. Next is the Kaohsiung Airport, which handles one flight in every 2.1 minutes. After about 5 p.m., the flights diminish gradually and finally all operations cease by 11:00 p.m. The international flights operate on a schedule similar to the domestic flights, but with a somewhat longer operation time span, starting around 6 a.m. and ceasing by midnight. We also investigated the hourly variation of LTO in 1999 and found few differences.

\subsection{Horizontal Distribution}

The horizontal distribution of aircraft emissions are analyzed according to the flight frequencies along the flight routes shown in Fig. 3. To give a sense of relative loading in each route, the flight frequencies are expressed in terms of the percentages of the total frequency. As shown in Fig. 6, about $80 \%$ of the domestic air traffic operates along the W4 route (cf. Fig. 3) over Western Taiwan, with more raffic over the north than over the south. Only about 10\% of the flights operate over Eastern Taiwan, and 10\% are offshore island flights. Such a pattern is roughly in accordance with the population distribution. 

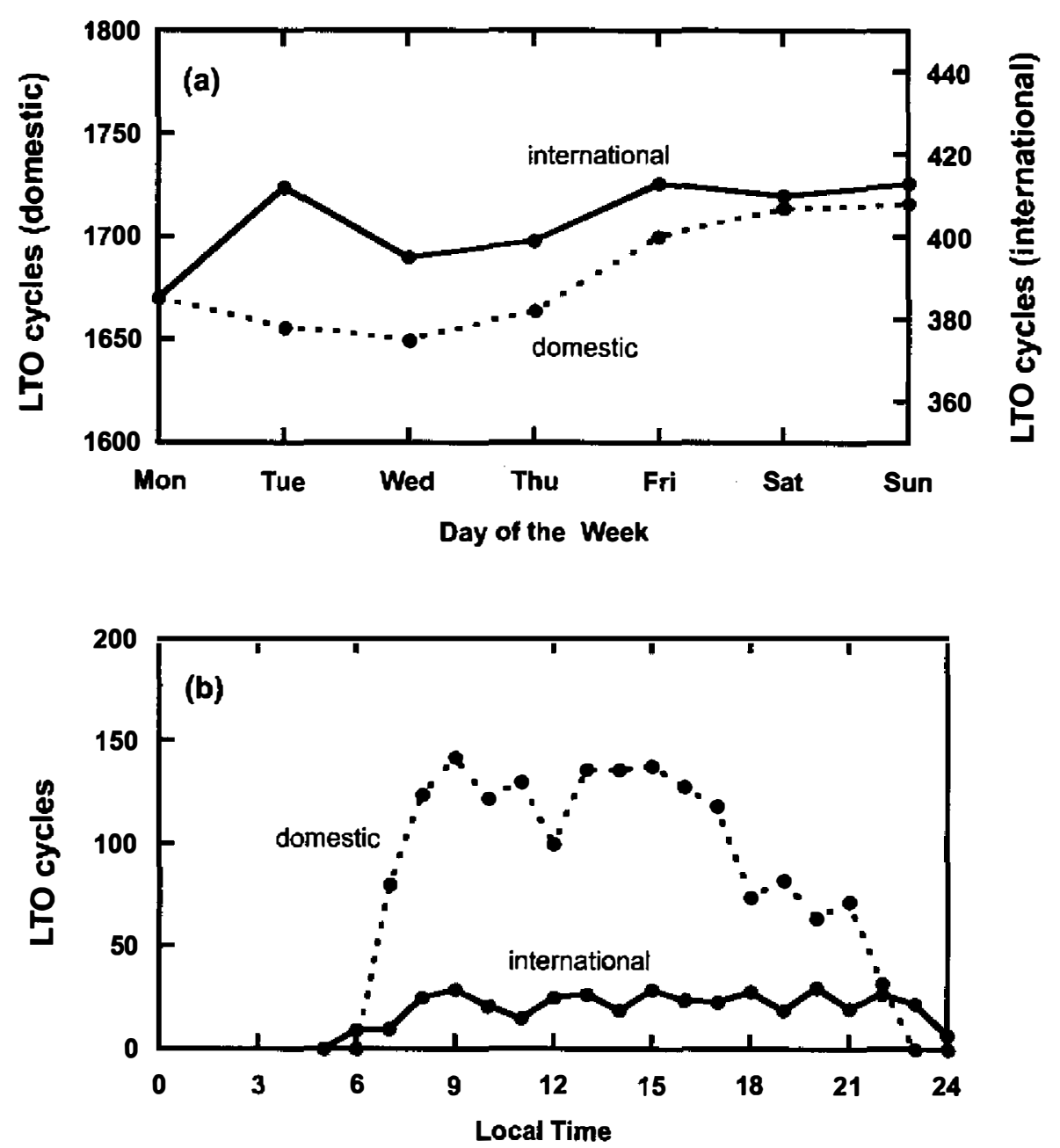

Fig. 5. Same as Fig. 4 but for (a) weekly variation in 1997, and (b) hourly variation in 1997.

The distribution of flights along the international corridors, as shown in Fig. 7, is obtained according to the way-point reports. There are two sets of way-points that are of particular significance to this study. Way-points APU and HCN (administrated by the Chiang Kai-Shek (TPE) and Kaohsiung (KHH) international airports, respectively) are the only points where an international flight may discontinue its normal operation (i.e., landing or takeoff). Thus, for the purpose of flight frequency and emission estimations, APU and HCN are taken as the dividing points of the flight routes. On the other hand, all international flights must pass through the way-points at the boundaries of the Taipei FIR. So, these way-points are taken as one end of the flight route, with the other end being either APU or HCN. However, the estimated flight frequency actually can be extended from these boundary points to the next flight terminal points (airports). Note that way-point reports at these boundary locations come 


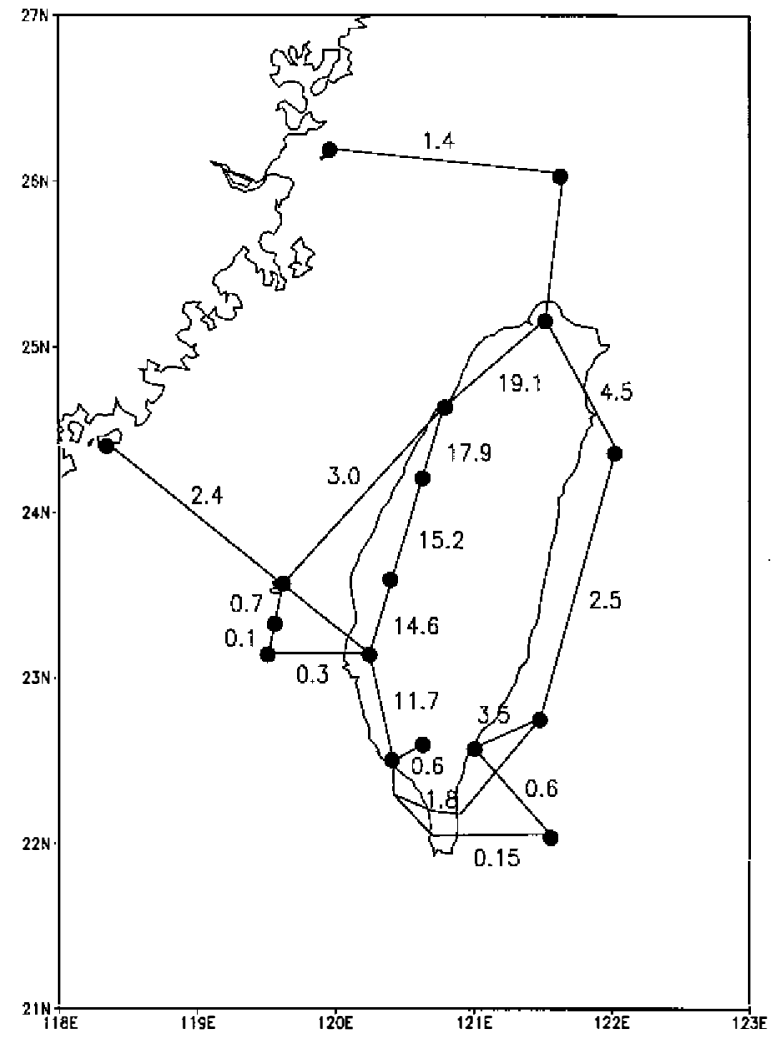

Fig. 6. Distribution of domestic flight frequencies (in percentage) over the Taipei FIR in 1997.

from all international flights including the over-flights. So, the LTO cycles discussed above represent only a portion of the total flight frequency needed for total emission estimation. By analyzing the more complete way-point reports of both 1997 and 1999, we were able to determine that the over-flights account for $35.1 \%$ of the total international flights. The possible error of this estimation should be similar to the difference between the frequency of LTO flights from the CAA report and that from the way-point reports. This difference is less than $5 \%$.

As shown in Fig. 7, the busiest international corridor is the A 1-Route, which connects the BLN, APU and ELA way-points. About $47.0 \%$ of the total international flights take this route, with $22.2 \%$ and $24.8 \%$ in the northern (BLN-APU) and southern (APU-ELA) sections, respectively. Note that the northwestern portion of the Taipei FIR actually overlaps with the Shanghai FIR, so there could be some flights going through that area but which are not accounted for. The busiest way-point is APU, which corresponds to the TPE International Airport (the major international airport in Taiwan). About $66 \%$ of the international flights in the Taipei FIR pass through this junction point. The rest of the flights must report to the other junction point - $\mathrm{HCN}$, which corresponds to the KHH International Airport.

At the southern end of the $\mathrm{Al}$ route lies the busiest boundary way-point - ELA. This major way-point between Taipei and Hong Kong meets 34.3\% of the international flights in the Taipei FIR. Another $32.8 \%$ of the flights register in at the northeastern boundary points - 


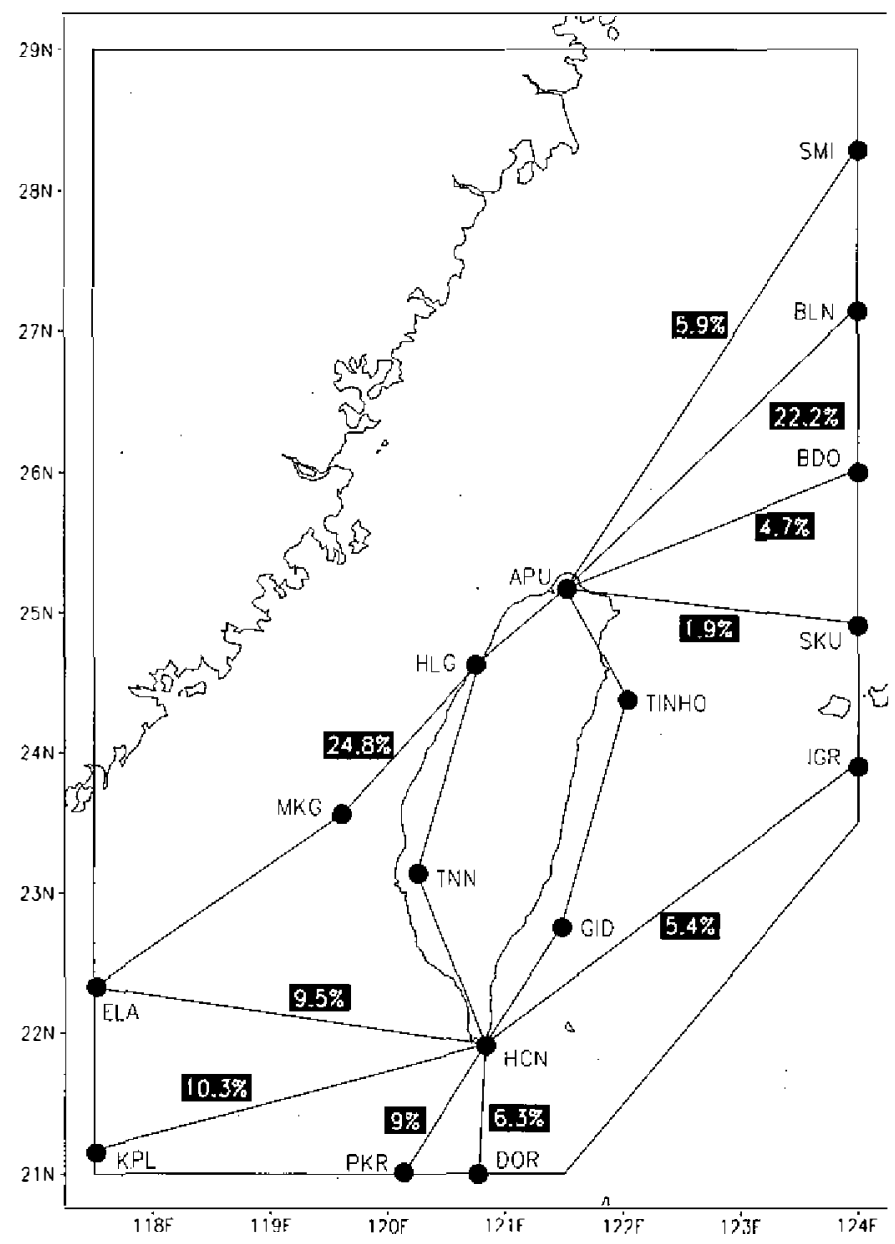

Fig. 7. Distribution of international flight frequencies (in percentage) over the Taipei FIR in 1997.

SMI, BLN and BDO — that host raffic to and from Japan, Korea and North America. Flights passing through the southern way-points KPL, PKR and DOR (hosting traffic to and from the Southeast Asian countries) account for yet another $25.6 \%$ of the flights. Note that the route DOR to HCN actually extends to APU, normally using route W4 for the northbound flights and route B591 for the southbound flights. Also note that routes M750 and R596 in Fig. 3 were not in use until 1998, so flights in these two corridors are not considered in our 1997 estimations.

\subsection{Vertical Distribution}

Because of the strong altitude dependence of background trace gas concentrations and their chemical and physical conversion rates, the vertical distribution of flights is an important factor in determining the effects of aircraft emissions. Under normal operations, international flights should remain at their cruising altitudes until they are about 70 miles ( 126 kilometers) within the airport perimeter. Therefore, the way-point reports of flights more than $126 \mathrm{~km}$ 
away from their departure and arrival airports can best provide the altitude distribution of cruising international flights. Figure 8a shows the vertical distribution (in $1 \mathrm{~km}$ interval) of flights reported at way-point ELA (cf. Fig. 2). This way-point is the southem boundary point of the A1 Route, which is the busiest international flight route in the Taipei FIR. All flights passing through this point must be international flights operating at their cruising altitudes. One can see from Fig. 8a that the international flights mostly cruise between 8 and $13 \mathrm{~km}$, with maximum frequency occurring at the 10 - and $12-\mathrm{km}$ levels. Such a distribution is very similar to that from reports at other boundary way-points, which also came solely from the international flights.

For the domestic flights, however, a way-point report is not mandatory because of the short flight distance. The way-point that does regularly receive pilot's reports of domestic
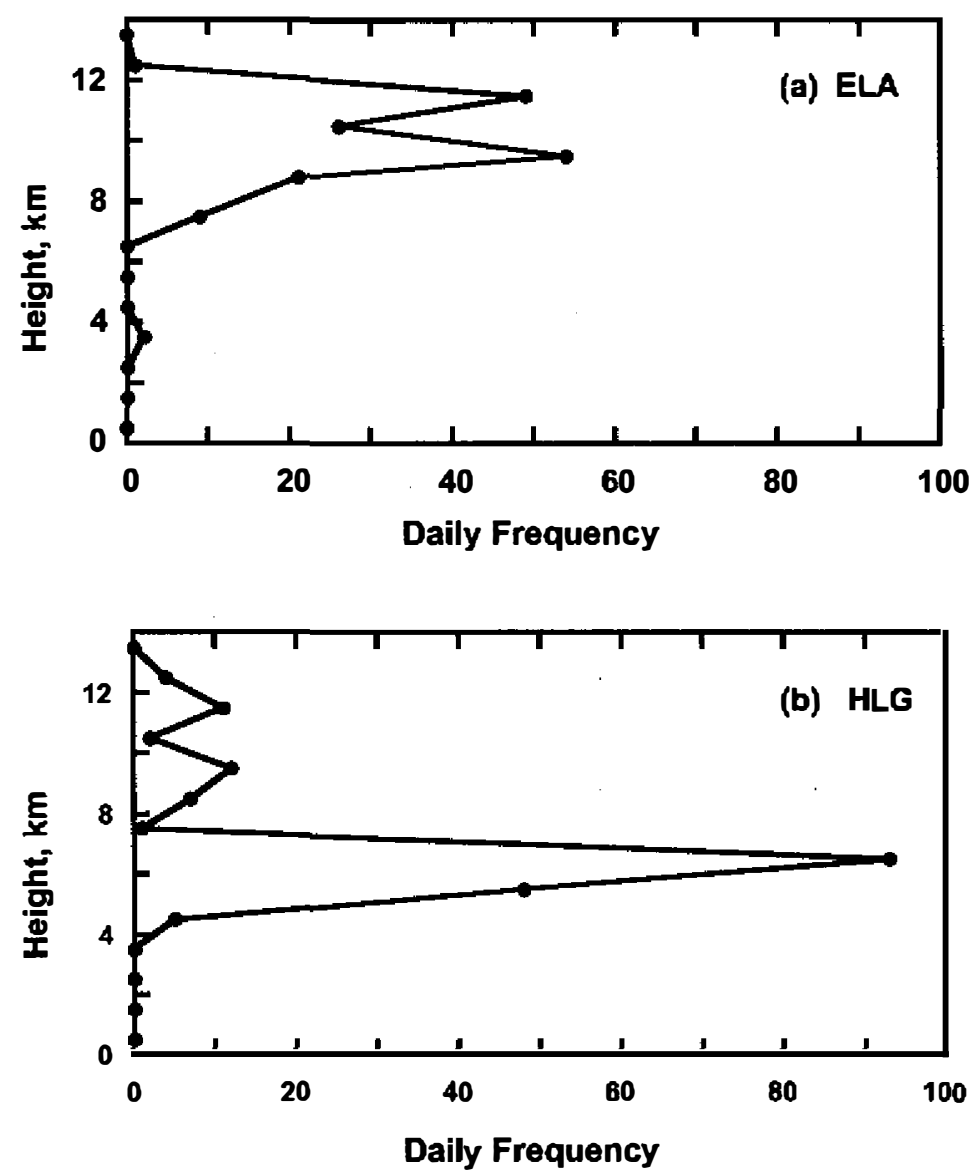

Fig. 8. Vertical distributions of flight frequency at (a) ELA, and (b) HLG. The geographic location of these way-points are shown in Fig. 2. The frequency is expressed in terms of the daily mean frequency (abscissa) in each one-kilometer height interval (ordinate). 
flights is HLG. Yet, it is not quite straightforward to obtain altitude distribution of domestic lights from the way-point reports at HLG. Because this way-point is located at the merging point of the northbound A1 Route and W4 Route, the reports might come from either domestic or international flights. Recall that A1 and W4 are the busiest international and domestic routs. Fortunately, the international flights are not required to give reports at this location unless it is a northbound flight in the W4 Route. Also, because of the short flights, domestic aircraft normally cruise at altitudes below $8 \mathrm{~km}$. We are thus able to tell that, in Fig. $8 \mathrm{~b}$, the minor peaks at altitudes above $9 \mathrm{~km}$ corresponds to the international flights, whereas the dominant peak at $6 \sim 7 \mathrm{~km}$ corresponds to the domestic flights.

\section{EMISSION INVENTORIES}

By putting the investigated parameters $N, Q, F$, and $T$ into Eq. (2), we were able to estimate the emissions of six chemical compounds from aircraft activity in the Taipei FIR during 1997. The overall annual productions of hydrocarbons, $\mathrm{CO}, \mathrm{NO}_{\mathrm{x}}$, sulfur, $\mathrm{CO}_{2}$ and water vapor are summarized in Table 5. Note that, because of the relatively large uncertainty in the overflight frequency (see Section 3d), we also present the estimations excluding the over-flights in the parentheses. To get a sense of their relative importance, these emission rates are further compared with those from ground transportation in Taiwan for the same period of time. As shown in Table 6, the emissions of hydrocarbons and $\mathrm{CO}$ amount to less than $1 \%$ of those from ground ransportation (EPA 1999). On the other hand, the productions of $\mathrm{NO}_{\mathrm{x}}$ and sulfur from aircraft are much more significant, reaching about $15 \%$ and $10 \%$, respectively, of those from the ground transportation. In the following we classify the total emissions into more detailed inventories.

Table 5. Estimated emissions (in kiloton per year) of six chemical from civil aircraft over the Taipei FIR during 1997. Values in the parentheses are for emissions excluding those from the over-flights.

\begin{tabular}{cccccc}
\hline $\mathrm{HC}$ & $\mathrm{CO}$ & $\mathrm{NO}_{\mathrm{x}}$ & $\mathrm{S}$ & $\mathrm{CO}_{2}$ & $\mathrm{H}_{2} \mathrm{O}$ \\
\hline 1.20 & 13.2 & 31.6 & 0.84 & 6733. & 2638. \\
$(1.1)$ & $(12.5)$ & $(25.5)$ & $(0.69)$ & $(5555)$. & $(2177)$. \\
\hline
\end{tabular}

Table 6. Ratios of annual emissions from civil aviation to those from ground transportation over the Taipei FIR during 1997. Values in the parentheses are for emissions excluding those from the over-flights.

\begin{tabular}{cccc}
\hline $\mathrm{HC}$ & $\mathrm{CO}$ & $\mathrm{NO}_{\mathrm{x}}$ & $\mathrm{S}$ \\
\hline $0.43 \%$ & $0.87 \%$ & $14.9 \%$ & $9.7 \%$ \\
$(0.40 \%)$ & $(0.83 \%)$ & $(12.0 \%)$ & $(8.0 \%)$ \\
\hline
\end{tabular}




\subsection{Different Altitude Levels}

Although we have shown that the total emission is significant for some of the chemicals but not others as compared with that from ground transportation, it is also important to realize that these emissions have a chemical-differentiated altitude dependence. The differentiation arises mainly from three factors: the operation time $\boldsymbol{T}$, fuel flow rate $\boldsymbol{F}$ and emission index $\boldsymbol{Q}$ associated with the operation mode at different levels. Civil aircraft run the take-off procedure with a full-power setting to lift the craft to 35 feet above the ground, then enter the climb-out mode up to 1000 feet with an $85 \%$ power output, and further lowering the power output while reaching the cruising altitude. During the approach and landing mode, a power output of $30 \%$ is used. As reflected in the emission indices in Table 3, different power outputs (and thus the combustion temperature) give different emission rates for each exhaust chemicals. The emissions of $\mathrm{CO}$ and $\mathrm{HC}$ are higher when the power output is lower. Just the opposite occurs in the emission of $\mathrm{NO}_{x}$, which is higher at higher power outputs.

To facilitate discussion for the altitude distribution, we group the idle and take-off modes as "ground" level, the climb-out and approach modes as the "near-surface" level, and call the cruise mode simply the "cruise" level. Table 7 summarizes the 1997 aircraft emissions at different altitude levels in the Taipei FIR. One can see that $\mathrm{HC}(60.4 \%)$ and $\mathrm{CO}(73.9 \%)$ are produced mainly on the ground level, reflecting their high emission indices in the idle mode. Due to the long operation time of the cruise mode, a significant portion of $\mathrm{HC}(36.2 \%)$ and CO (24.2\%) are also produced at the cruise levels. Note that emissions at the cruise levels normally extend over a much broader horizontal area than the other two levels, not only because of the physical locations but also the stronger upper-air winds. All other chemicals are emitted predominantly ( $>80 \%$ ) at the cruise levels, mainly because of the longer operation times. The ratio is even higher for $\mathrm{NO}_{\mathrm{x}}(84.8 \%)$ because of the higher emission index in the cruise mode.

\subsection{Domestic Versus International}

In Fig. 4a, we showed that the frequency of domestic flights is about 3 times that of international flights. Yet, Table 8 shows that the emissions of $\mathrm{H}_{2} \mathrm{O}, \mathrm{CO}_{2}, \mathrm{~S}$, and $\mathrm{NO}_{\mathrm{x}}$ from

Table 7. Estimated percentages of aircraft emission at different vertical levels over the Taipei FIR during 1997. Values in the parentheses are for emissions excluding those from the over-flights.

\begin{tabular}{ccccccc}
\hline & $\mathrm{HC}$ & $\mathrm{CO}$ & $\mathrm{NO}_{\mathrm{x}}$ & $\mathrm{S}$ & $\mathrm{CO}_{2}$ & $\mathrm{H}_{2} \mathrm{O}$ \\
\cline { 2 - 7 } Ground & 60.4 & 73.9 & 5.6 & 11.5 & 11.5 & 11.5 \\
& $(66.0)$ & $(78.0)$ & $(7.0)$ & $(13.9)$ & $(13.9)$ & $(13.9)$ \\
\cline { 2 - 7 } Near surface & 3.4 & 1.9 & 9.6 & 8.2 & 8.2 & 8.2 \\
& $(4.0)$ & $(2.0)$ & $(11.9)$ & $(10.0)$ & $(10.0)$ & $(10.0)$ \\
\cline { 2 - 7 } Cruise levels & 36.2 & 24.2 & 84.8 & 80.3 & 80.3 & 80.3 \\
& $(30.0)$ & $(20.0)$ & $(81.1)$ & $(76.1)$ & $(76.1)$ & $(76.1)$ \\
\hline
\end{tabular}


international flights far exceed those from the domestic flights. This is mainly due to the longer flight distance (operation time) for the international flights. For $\mathrm{HC}$ and $\mathrm{CO}$, however, the situation is not the same. The domestic flights spend more time in the idle mode (which is directly proportional to the LTO frequency), and thus have higher average emission indices for $\mathrm{HC}$ and $\mathrm{CO}$ (see the discussions above). So, the ratio of $\mathrm{HC}$ from domestic flights to that from international flights is very close to one. In contrast, the ratios are $0.55 \mathrm{for}_{2} \mathrm{O}, \mathrm{CO}_{2}$ and $\mathrm{S}$, and 0.47 for $\mathrm{NO}_{\mathrm{x}}$. The ratio for $\mathrm{CO}(2.66)$ is even higher than that for $\mathrm{HC}$. This difference is caused mainly by the propeller aircraft, which have a very high $\mathrm{CO}$ emission index compared with that of jet aircraft, but not as high as indicated in the HC emission index (see Table 3). In fact, the idle-mode emission index is lower for propeller than for jet aircraft. More details on the role of propeller aircraft are discussed next.

\subsection{Different Aircraft Types}

From the discussions above, we know that the emissions of domestic flights are different than those of international flights, not only because of the relative difference in time spent during each operation mode, but also due to the variation of emission indices among aircraft types. Table 9 summarizes the total emission of each chemicals from different types of aircraft. Because of their high flight frequencies and long overall operation times, passenger jets are responsible for $85 \%$ of the $\mathrm{H}_{2} \mathrm{O}, \mathrm{CO}_{2}$ and $\mathrm{S}$ emissions, as well as $88 \%$ of the $\mathrm{NO}_{\mathrm{x}}$ emission in the Taipei FIR. The rest of the emissions are divided in roughly equal proportions between the cargo jets and the propeller aircraft. Note that the ratios we obtained for cargo jets are quite similar to those by Baughcum et al. (1996), who showed that the emissions from Boeing 747 Cargo jets over North Pacific were $7 \%$ of the total civil aviation. The ratio of $\mathrm{HC}$ emissions from the passenger jets is somewhat smaller due to the relatively low emission indices for this aircraft type, but still stands at a commanding value of $75 \%$. The $\mathrm{CO}$ emissions are another story. Most of them were emitted by the propeller aircraft and, according to the analysis in Table 7, on the ground. Since essentially all propeller aircraft pertain to domestic flights, it is not surprising that $\mathrm{CO}$ is produced mostly by the domestic flights as discussed in the previous section (e.g., Table 8).

\section{SUMMARY AND DISCUSSION}

The temporal and spatial distributions of flight frequencies by civil aircraft in the Taipei FIR for the year 1997 are analyzed in this study. In addition, emission indices of six chemicals ( $\mathrm{HC}, \mathrm{CO}, \mathrm{NO}_{\mathrm{x}}$, sulfur, $\mathrm{CO}_{2}$ and $\mathrm{H}_{2} \mathrm{O}$ ), as well as fuel flow rates, pertaining to the flights operated in the Taipei FIR are derived for different aircraft types and operation modes. These two data sets are then compiled to obtain an inventory of aircraft emissions. The estimated annual emission of the 6 chemicals over the Taipei FIR in 1997 was 1.20, 13.2, 31.6, 0.84, 6569 and 2574 kilotons for $\mathrm{HC}, \mathrm{CO}, \mathrm{NO}_{\mathrm{x}}, \mathrm{S}, \mathrm{CO}_{2}$ and $\mathrm{H}_{2} \mathrm{O}$, respectively. These emissions are further classified according to the aircraft types, the altitude level of flights, and whether they are produced by domestic or international flights.

Are these aircraft emissions a noteworthy environmental issue in the Taiwan area? Let us 
Table 8. Percentages of aircraft emissions from domestic and international traffic over the Taipei FIR during 1997. Values in the parentheses are for emissions excluding those from the over-flights.

\begin{tabular}{ccccccc}
\hline \multirow{5}{*}{ Domestic } & $\mathrm{HC}$ & $\mathrm{CO}$ & $\mathrm{NO}_{\mathrm{x}}$ & $\mathrm{S}$ & $\mathrm{CO}_{2}$ & $\mathrm{H}_{2} \mathrm{O}$ \\
\cline { 2 - 8 } & 49.2 & 72.7 & 31.8 & 35.6 & 35.6 & 35.6 \\
& $(53.8)$ & $(76.6)$ & $(39.4)$ & $(43.4)$ & $(43.4)$ & $(43.4)$ \\
\cline { 2 - 8 } International & 50.8 & 27.3 & 68.2 & 64.4 & 64.4 & 64.4 \\
& $(46.2)$ & $(23.4)$ & $(60.6)$ & $(56.6)$ & $(56.6)$ & $(56.6)$ \\
\hline
\end{tabular}

Table 9. Estimated percentages of aircraft emissions from different aircraft types over the Taipei FIR during 1997. Values in the parentheses are for emissions excluding those from the over-flights.

\begin{tabular}{ccccccc}
\hline & $\mathrm{HC}$ & $\mathrm{CO}$ & $\mathrm{NO}_{x}$ & $\mathrm{~S}$ & $\mathrm{CO}_{2}$ & $\mathrm{H}_{2} \mathrm{O}$ \\
\cline { 2 - 7 } Passenger jet & 75.2 & 44.9 & 87.9 & 85.0 & 85.0 & 85.0 \\
& $(74.0)$ & $(42.5)$ & $(87.7)$ & $(84.6)$ & $(84.6)$ & $(84.6)$ \\
\cline { 2 - 7 } Cargo jet & 14.7 & 5.4 & 9.1 & 8.1 & 8.1 & 8.1 \\
& $(15.0)$ & $(5.1)$ & $(8.6)$ & $(7.4)$ & $(7.4)$ & $(7.4)$ \\
\cline { 2 - 7 } Propeller aircraft & 10.1 & 50.3 & 3.0 & 6.9 & 6.9 & 6.9 \\
& $(11.0)$ & $(52.4)$ & $(3.7)$ & $(8.0)$ & $(8.0)$ & $(8.0)$ \\
\hline
\end{tabular}

first compare the amount of aircraft emissions with other pollution sources. There were about 14 million automobiles but only 859 flights operating daily in Taiwan during 1997. It may seem that the emissions from aircraft are insignificant compared with the ground ransportation. Yet, according to the Annual Report of the Institute of Transportation (ITMTC 1998), civil aircraft were responsible for $16.6 \%$ of the passenger-kilometers in Taiwan, whereas the pavedroad and railroad systems handled the other $54.4 \%$ and $29 \%$, respectively. In the previous section, we also showed that the annual emission of sulfur and $\mathrm{NO}_{\mathrm{x}}$ from aircraft in the Taipei FIR reached about $10 \%$ and $15 \%$ of those from the ground transportation. It is true that most of these pollutants are emitted directly in the upper troposphere, and past studies on aircraft emission focus mostly on their direct and indirect effects on the radiation budget (e.g., Arnald et al. 1981; Karcher 1995; Schumann 1997). But, this does not mean that they are not important to the surface air pollution problem. On the other hand, although the emissions of $\mathrm{HC}$ and $\mathrm{CO}$ from aircraft is less than $1 \%$ of that from the ground transportation, most of them are emitted at the ground level within the airport perimeter. One may get an idea of their possible effect on air pollution by comparing the unit-area emissions with those in the surrounding area.

The Taipei domestic airport is situated in the Songshang District of the Taipei City. With substantial emission of pollutants from the motor vehicles, the Songshang District (about 10.6 
$\mathrm{km}^{2}$ in size) produces $\mathrm{HC}, \mathrm{CO}, \mathrm{NO}_{\mathrm{x}}$ and $\mathrm{S}$ at rates of 560, 1610, 303 and 20.1 tons $\mathrm{km}^{-2}$ annually (EPA 1999). Our estimation showed these rates are 43.9, 572, 127 and 6.64 tons $\mathrm{km}^{-2}$ in the Taipei Airport (about $4 \mathrm{~km}^{2}$ in size), reaching about $1 / 3$ of those in the Songshang District except for HC. If the airport is away from the urban area, its production of pollutants can be even more significant. For instance, the TPE International airport is situated in a suburban area of the Taoyuan County, where some light industry resides. The annual emissions of $\mathrm{HC}, \mathrm{CO}, \mathrm{NO}_{\mathrm{x}}$ and $\mathrm{S}$ in this area are 70.2, 180.5, 50.1, and 38.5 tons $\mathrm{km}^{-2}$ (EPA 1999). In contrast, the airport produces more $\mathrm{CO}\left(297.8\right.$ tons km $\left.\mathrm{yr}^{-1}\right)$ and $\mathrm{NO}_{\mathrm{x}}\left(122.8\right.$ tons $\left.\mathrm{km}^{-2} \mathrm{yr}^{-1}\right)$ and slightly less $\mathrm{HC}\left(61.0\right.$ tons $\left.\mathrm{km}^{-2} \mathrm{yr}^{-1}\right)$, but much less $\mathrm{S}\left(5.1\right.$ tons $\left.\mathrm{km}^{-2} \mathrm{yr}^{-1}\right)$ per unit area. Because of the different emission scenarios, one may expect the two airports to have contrasting influences on the surrounding area. However, more detailed studies are necessary for a full understanding.

The relative significance of aircraft emissions in the Taipei FIR can also be demonstrated by comparing them with those over other regions. Ma and Zhou (1999) estimated the $\mathrm{NO}_{\mathrm{x}}$ emission from civil aviation over Mainland China during 1997 and 1998 to be 44.6 kilotons per year, which is only $45 \%$ greater than that over the Taipei FIR. Such a difference is rather small considering the differences in size and population of the two areas. There is no data on the emissions for the whole of Asia because of a lack of similar studies in this overall region. But, we can check the global values. IPCC (1999) estimates that globally 60 kilotons of sulfur were emitted from aircraft activities in 1992. If one may extrapolate this rate by taking the mean growth of 5\% per year, then the sulfur emissions in the Taipei FIR (which occupies 0. $12 \%$ of the Earth's surface) would amount to $1.1 \%$ of the world emissions. Note that a similar ratio $(1.36 \%)$ exists in the LTO over the Taipei-FIR relative to that over the whole world (ACI 1997), and such consistency gives us some confidence on the our estimated emission inventory. But, there are even better ways of determining the uncertainties in our emission inventory.

The first uncertainty in our emission inventory is from inaccuracies in the emission index. Out estimations are generally within $20 \%$ of those in Brasseur et al. (1998), and at least part of the discrepancies arise simply from the differences in aircraft types used in different areas. Uncertainties may also arise from the fact that all the available emission indices were laboratory-based measurements, which did not consider the influence of payload. Baughcum et al. (1996) estimate that the deviation caused by payload ranges from $0.8 \%$ to $7.7 \%$. The mean cargo and passenger loads in the Taipei FIR are 1.7 tons and 92 persons per aircraft. However, we lack of further information to quantify the payload effect on the total emissions.

There are also possible errors in the statistics of flight frequencies. We compared the frequencies derived from the flight timetable and the way-point reports (for intemational flights only) with those from the CAA Report for both 1997 and 1999. For domestic flights, the flight timetables give $18.6 \%$ and $8.7 \%$ more flights than in the CAA Reports for the two years. For international flights, the timetables give $8.6 \%$ and $0.2 \%$ more flights. Since there might have been flight cancellations that caused the discrepancies, we used the frequencies from the CAA Report. As mentioned in the previous section, the way-point reports also provided information on the frequency of international flights that were either landing or takeoff. This dataset gives $20.7 \%$ and $4.7 \%$ less frequencies than the CAA Report for 1997 and 1999, respectively, possibly due to the omission of reports by a few pilots or the incompleteness of the dataset we 
obtained. Of course, there is always the possibility of errors in the CAA Report as well. Overall, it seems that the data sets of 1999 are more consistent than the 1997 data sets, and the international data sets are more consistent than the domestic datasets.

Finally, our inventory does not include contributions from a few aircraft types. The emissions from police or private aircraft are quite minor and are thus safe to ignore in the Taipei FIR. There could be substantial contributions from military aircraft. However, it is difficult to obtain detailed information to evaluate military emissions. According to IPCC (1999), the ratio of worldwide emissions by civil to military aviation was about $82: 18$ in 1992 , but is expected to decrease to 93:7 in 2015. These numbers might provide us some rough idea of the amount of emissions from military aircraft in the Taipei FIR.

Acknowledgements This work was supported by the National Sciences Council Grant NSC872621-P-117-001. The authors are grateful to the Civil Aeronautics Administration, Ministry of Transportation and Communications, R.O.C. for providing the crucial datasets.

\section{REFERENCES}

ACI, 1997: Monthly Worldwide Airport Traffic Report. Airports Council International.

ARIT, 1998: Transportation Systems Status and Capacity in Taiwan Area, 1997. Annual Report, Institute of Transportation, Ministry of Transportation and Communications, R.O.C., 143 pp. (in Chinese)

Arnold, F., R. Fabian, and W. Joos, 1981: Measurements of the height variation of sulfuric acid vapor concentrations in the stratosphere. Geophys. Res. Lett., 8, 293-296.

ATAG, 1997: Asia/Pacific Air Traffic Growth \& Constraints. Air Transport Action Group, Geneva, Switzerland, $50 \mathrm{pp}$.

Baughcum, S. L., 1996: Subsonic aircraft emissions inventories. In: Atmospheric Effects of Aviation: First Report of the Subsonic Assessment Project. NASA Reference Publication 1385, 15-29.

Baughcum, S. L. , S. C. Henderson, T. G. Tritz, and D. C. Pickett, 1996: Scheduled Civil Aircraft Emission Inventories for 1992: Database Development and Analysis. NASACR-4700, National Aeronautics and Space Administration, Langley Research Center, Hampton, VA, USA, $196 \mathrm{pp}$.

Brasseur, G. P., R. A. Cox, D. Hauglustaine, I. Isaksen, J. Lelieveld, D. H. Lister, R. Sausen, U. Schumann, A. Wahner, and P. Wiesen, 1998: European scientific assessment of the atmospheric effects of aircraft emissions. Atmos. Environ., 32, 2329-2418.

CAA, 1998: The Monthly Statistics Report of Commercial Aircraft Transport. Civil Aeronautics Administration, R. O. C., 164 pp. (in Chinese)

EPA, 1999: The Pre-operation for the Volume Emission Control of Air Pollutants and the Recommended Methods for the Emission Estimation. Report number EPA-88-F31-031059, Environmental Protection Administration, R. O. C. (in Chinese)

Fortuin, J. P. F., R. van Dorland, W. M. F. Wauben, and H. Kelder, 1995: Greenhouse effects of aircraft emissions as calculated by a radiative transfer model. Ann. Geophysicae, 13, 413-418. 
Gardner, R. M., 1998: ANCAT/EC2 Aircraft Emission Inventories for 1991/1992 and 2015: Final Report. EUR-18179, ANCAT/EC Working Group, ISBN-92-828-1924-6, 84 pp.

IATA, 1996a: World Air Transportation Statistics. International Air Transport Association, Geneva, Switzerland, 40th ed., $111 \mathrm{pp}$.

IATA, 1996b: Environmental Review 1997. Intermational Air Transport Association, Geneva, Switzerland, 103 pp.

IATAG, 1998: International Airline Guide 98-99. EPS Aviation Publishers, 388pp.

ICAO, 1993: International Standards and Recommended Practices, Environmental Protection. Annex 16 to the Convention on International Civil Aviation, Volume II, Aircraft Engine Emissions. International Civil Aviation Organization, Montreal, Canada, 2nd., 55 pp.

ICAO, 1995: ICAO Engine Exhaust Emissions Databank. 1st Edition-1995. ICAO-9646AN/943, International Civil Aviation Organization, Montreal, Quebec, Canada, 53 pp.

IPCC, 1996: Climate Change 1995: The Science of Climate Change. Contribution of Working Ggroup I to the Second Assessment Report of the Intergovernmental Panel on Climate Change. In: Houghton, J. T., L. G. Meria Filho, B. A. Callander, N. Harris, A. Kattenberg, and K. Maskell (Eds.), Cambridge University Press, Cambridge, United Kingdom and New York, 572 pp.

IPCC, 1999: Aviation and the Global Atmosphere. In: Penner, J. E., D. H. Lister, D. J. Griggs, D. J. Dokken, and M. Mcfarland (Eds.), Cambridge University Press, 373 pp.

ITMTC, 1998: Transportation systems status and capacity in the Taiwan area, 1997. Annual Report, Institute of Transportation, Ministry of Transportation and Communications, R. O. C., 143 pp.

Karcher, B., 1995: A trajectory box model for aircraft exhaust plumes. J. Geophys. Res., 100, $18835-18844$.

Ma, J., and X. Zhou, 1999: Development of a three-dimensional inventory of aircraft $\mathrm{NO}_{\mathrm{x}}$ emissions over China. Atmos.Environ. 34, 389-396.

Schumann, U., 1997: The impact of nitrogen oxides emissions from aircraft upon the atmosphere at flight altitudes - Results from the Aeronox project. Atmos. Environ., 31, 17231733.

Zhao, J., and R. P. Turco, 1995: Nucleation simulations in the wake of a jet aircraft in stratospheric flight. J. Aerosol Sci., 26, 779-795. 